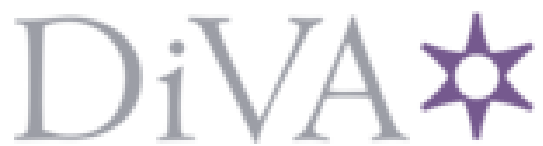

http://www.diva-portal.org

This is the published version of a paper published in Nordic Pulp \& Paper Research Journal.

Citation for the original published paper (version of record):

Nordström, B., Hermansson, L. (2017)

Effect of fiber length on formation and strength efficiency in twin-wire roll forming

Nordic Pulp \& Paper Research Journal, 32(1): 119-125

https://doi.org/10.3183/NPPRJ-2017-32-01-p119-125

Access to the published version may require subscription.

N.B. When citing this work, cite the original published paper.

Permanent link to this version:

http://urn.kb.se/resolve?urn=urn:nbn:se:ri:diva-30339 


\section{Effect of fiber length on formation and strength efficiency in twin-wire roll forming}

\section{Bengt Nordström and Lennart Hermansson}

KEYWORDS: Kraft pulps, Fiber length, Twin wire machines, Consistency, Formation, Tensile strength, $\mathrm{Z}$ direction strength

SUMMARY: A change in fiber length is known to change fiber flocculation and formation of machine-made paper, but it has been unclear how a change in formation through fiber length affects strength efficiency. (The strength efficiency reflects how well the furnish strength, as indicated by the handsheet strength, is utilized in the machine-made paper.) The effect of fiber length on strength efficiency in twin-wire roll forming was presently investigated by examining two furnishes with different average fiber length, prepared from the same batch of softwood kraft pulp, over a wide range of headbox consistencies on a pilot machine.

An increase in fiber length resulted not only in worse Ambertec formation over the whole range of headbox consistencies but also in faster relative deterioration of the formation with increasing consistency. Tensile strength efficiency and Z-strength efficiency were both reduced when the formation was impaired through increased fiber length, and the effect was similar to the effect of a corresponding change in formation through headbox consistency. A given change in formation, through fiber length or headbox consistency, had a larger relative effect on Z-strength efficiency than on tensile strength efficiency.

\section{ADDRESSES OF THE AUTHORS:}

Bengt Nordström (bengt.e.nordstrom@sca.com), SCA R\&D Centre, P.O. Box 716, SE-851 21 Sundsvall, Sweden;

Lennart Hermansson (lennart.hermansson@ri.se), RISE Bioeconomy, P.O. Box 5604, SE-114 86 Stockholm, Sweden.

\section{Corresponding author: Bengt Nordström}

An increase in fiber length promotes high tensile strength for handsheets (Nordström 2014; Page 1969), whereas the extent with which this is reflected in higher strength for machine-made paper depends on how the strength efficiency is affected by a change in fiber length. The strength efficiency represents a measure of how well the strength potential of the furnish is utilized in the machinemade paper, and it is given by the strength of the machinemade paper in relation to the strength of handsheets made from the same furnish. An increase in fiber length tends to give higher fiber flocculation tendency and impaired formation. All other things being equal, worse formation or a more uneven local mass distribution in the plane of the sheet can be expected to result in a more uneven stress distribution under load in tension, and thereby a lower tensile strength efficiency. Accordingly, impaired formation through increased headbox consistency is associated with lower tensile strength efficiency in twinwire roll forming, as demonstrated for recycled furnishes
(Nordström 2003d) and softwood kraft furnishes (Nordström, Hermansson 2016). However, it is unclear how a change in formation through fiber length affects strength efficiency, as there is no universal relationship between strength efficiency and formation.

Tensile strength efficiency tends to decrease rather than increase when the formation is improved through the jetto-wire speed difference (Nordström 2003d) or blade pulses in twin-wire forming. The adverse effect of blade pulses on tensile properties despite improved formation is observed when comparing blade versus roll forming (Nordström 2003e) and roll-blade versus roll forming (Nordström 2003e; Nordström 2006; Nordström, Norman 1996). Moreover, roll-blade forming with a larger proportion of blade dewatering has been observed to result in lower tensile strength despite better formation (Nordström 2003b). The decrease in tensile properties produced by blade pulses or the jet-to-wire speed difference is interpreted as being due to a deterioration of the deposited fiber mats caused by the applied shear stresses, with an impairment of the subsequent establishment of fiber-to-fiber bonds.

Another example of the complex relationship between tensile strength efficiency and formation is given by a comparison of fourdrinier forming with roll forming. At a given headbox consistency, twin-wire roll forming has been shown to produce substantially better formation than does fourdrinier forming, whereas this is not reflected in any higher tensile strength efficiency at a jet-to-wire speed difference corresponding to the point of minimum shear (Nordström 2003c). The better formation for roll forming is considered to be chiefly a result of a faster dewatering event with less time for reflocculation.

Whereas there appears to be no previous report revealing the effect on strength efficiency related to a change in fiber length alone, there are investigations in which formation was changed through the furnish. Nordström (2003a) observed similar tensile strength efficiency in roll forming for hardwood and softwood kraft furnishes despite a substantial difference in the formation of the machinemade paper between the two furnish types. This may be related to the fact that the relative formation difference between handsheets and machine-made paper (i.e., the machine-to-handsheet ratio for formation) was similar for the softwood and hardwood furnishes at the point of minimum shear during dewatering. There was thus a substantial difference also in the handsheet formation between the softwood and hardwood furnishes, which reflects the difference in cross-sectional fiber dimensions between the two furnish types. Hallgren and Lindström (1989) reported higher strength efficiency in roll forming for a hardwood furnish than for a softwood furnish, and this was attributed to the better formation for the hardwood furnish. Hallgren and Lindström used laboratory sheets made in a dynamic sheet former instead of conventional 
handsheets for evaluation of the furnish strength, and they did not provide the formation of the laboratory sheets. In roll forming of two testliner furnishes, the furnish giving best formation also showed highest strength efficiency (Nordström 2003d). The tensile strength efficiency in roll forming of LWC base paper furnishes was increased when using a mechanical pulp component giving better formation, that is, when going from spruce-TMP to spruceSGW (Nordström 2006). In some investigations, higher tensile strength efficiency has thus been noted for furnishes showing better formation, but the isolated effect of fiber length is not revealed in the earlier reports.

In this work, the effect of fiber length on strength efficiency in twin-wire roll forming is investigated by examining two furnishes with different fiber length distributions prepared from the same batch of softwood kraft pulp.

\section{Materials and Methods}

Two furnishes with different fiber length were evaluated in twin-wire roll forming on the pilot machine at RISE Bioeconomy. Each furnish was examined over a series of headbox consistencies. The grammage was $64-69 \mathrm{~g} / \mathrm{m}^{2}$, with a single experimental point at $77 \mathrm{~g} / \mathrm{m}^{2}$ (highest headbox consistency for the furnish with the longest fiber length). General descriptions of the pilot machine system have been given by Röding and Norman (1986) and Nordström (1995).

\section{Furnishes}

Never-dried unbleached softwood kraft pulp with a kappa number of about 48 was used in the investigation. The ratio between pine (Pinus sylvestris) fibers and spruce (Picea abies) fibers in the pulp was 71:28. The pulp was taken at a dry solids content of 10-15\%, immediately after the pulp washing stage in the Obbola linerboard mill (SCA). All pulp required for the investigation was filled into containers on one occasion, keeping track of the order in which the containers were filled. The pulp in every second container was used for one furnish (one

Table 1 - Properties for the two furnishes. Fiber length given as the length-weighted average for the contour length. Water retention value (WRV) and fiber saturation point (FSP) measured on the fiber fraction after adjustment to $\mathrm{pH} 7.8$.

\begin{tabular}{cccccc}
\hline $\begin{array}{c}\text { Fiber length } \\
(\mathbf{m m})\end{array}$ & $\begin{array}{c}\text { Fiber curl } \\
\text { index } \\
(\%)\end{array}$ & SR & $\begin{array}{c}\text { Fines } \\
\mathbf{( \% )}\end{array}$ & $\begin{array}{c}\text { WRV } \\
(\mathbf{g} / \mathbf{g})\end{array}$ & $\begin{array}{c}\text { FSP } \\
(\mathbf{g} / \mathbf{g})\end{array}$ \\
\hline $1.99 \pm 0.02$ & $14.1 \pm 0.5$ & 21 & 6 & 1.67 & 1.56 \\
$2.57 \pm 0.04$ & $13.7 \pm 0.6$ & 17 & 4 & 1.58 & 1.53 \\
\hline
\end{tabular}

Table 2 - Handsheet properties for the two furnishes.

\begin{tabular}{ccccc}
\hline $\begin{array}{c}\text { Fiber } \\
\text { length } \\
(\mathbf{m m})\end{array}$ & $\begin{array}{c}\text { Amb. } \\
\text { formation } \\
(\mathrm{V} / \mathrm{g} / \mathrm{m})\end{array}$ & $\begin{array}{c}\text { Density } \\
\left(\mathbf{k g} / \mathrm{m}^{3}\right)\end{array}$ & $\begin{array}{c}\text { Tensile } \\
\text { index } \\
(\mathbf{k N m} / \mathbf{k g})\end{array}$ & $\begin{array}{c}\text { Z-strength } \\
\left(\mathbf{k N} / \mathbf{m}^{2}\right)\end{array}$ \\
\hline 2.0 & $0.39 \pm 0.01$ & $727 \pm 9$ & $80 \pm 3$ & $971 \pm 38$ \\
2.6 & $0.40 \pm 0.01$ & $730 \pm 3$ & $90 \pm 4$ & $962 \pm 20$ \\
\hline
\end{tabular}

fiber length level), whereas the remaining pulp was used for the other furnish. This was done to minimize any difference in unrefined pulp properties between the two furnishes.

The pulps for both furnishes were refined to a specific energy of $100 \mathrm{kWh} / \mathrm{t}$ at a consistency of $4 \%$ after adjustment to $\mathrm{pH}$ 9.0. The furnish with relatively short fibers was obtained by refining with a high degree of fiber shortening using a 24-inch double-disc refiner (Beloit) in one stage. The rotational speed was $750 \mathrm{r} / \mathrm{min}$, and the fillings had a cutting edge length of $6.13 \mathrm{~km} / \mathrm{rev}$ and dams to reduce the flow in the grooves. The specific edge load was $2.0 \mathrm{Ws} / \mathrm{m}$.

The furnish with relatively long fibers was obtained by refining with a minimum of fiber shortening. Two-stage refining was used, and the two conical refiners had the same design (Jylhävaara JC-00) and were similarly operated. Each stage thus introduced half of the refining energy. The rotational speed was $1000 \mathrm{r} / \mathrm{min}$, and the fillings had a cutting edge length of $1.8 \mathrm{~km} / \mathrm{rev}$. The specific edge load was $1.5 \mathrm{Ws} / \mathrm{m}$.

Table 1 provides properties for the two furnishes. The values for fiber length, fiber curl index, and SR represent mean values of five separate samples per furnish, taken during the pilot machine investigation. Mean values of two samples (first and last sample of each series) are provided for fines content, WRV, and FSP. Whereas the different refining conditions produced substantially different fiber length levels, the fiber curl index was similar for the two furnishes. The difference in SR number between the furnishes is chiefly attributed to the difference in fines content. The difference in fiber swelling was limited, as indicated by WRV and FSP.

Table 2 provides handsheet properties for the two furnishes. Handsheets were prepared from each of the five separate pulp samples taken per furnish during the pilot machine investigation. $\mathrm{pH}$ of the pulp was adjusted to 7.8 before sheet making. The handsheets were made with a nominal oven-dry grammage of $60 \mathrm{~g} / \mathrm{m}^{2}$ according to ISO 5269-1, except for the wet-pressing pressure. A pressure of $700 \mathrm{kPa}$ (same pressure in both steps) was used for the furnish with a fiber length of $2.0 \mathrm{~mm}$ to obtain a density of the handsheets corresponding to the density of the machine-made paper. A pressure of $800 \mathrm{kPa}$ was used for the furnish with a fiber length of $2.6 \mathrm{~mm}$. The conditions employed resulted in similar handsheet density and Zstrength for the two furnishes, whereas significantly higher tensile strength was noted for the furnish with longer fibers. The two furnishes showed similar Ambertec formation, which is reasonable considering the suppression of fiber flocculation in handsheet preparation. No retention agent or strength additive was used.

\section{Forming}

The forming roll (Nordström, Norman 1994) had a diameter of $1.635 \mathrm{~m}$, and the roll wrapping angle was $78^{\circ}$. The vacuum levels in the three suction zones of the forming roll were $-3,-3$, and $-10 \mathrm{kPa}$, as given in MD.

The inner and outer wires were both of the sheet support binder (SSB) type. They had 910 support points per $\mathrm{cm}^{2}$ and were 2-shed on the paper side and 5-shed on the 
machine side. Both wires had a tension of $8.0 \mathrm{kN} / \mathrm{m}$, and the wire speed was $600 \mathrm{~m} / \mathrm{min}$.

The hydraulic headbox employed had 10 tube rows and an inner width of $0.33 \mathrm{~m}$. Except for the vanes, refer to Nordström (2003c) for a description of the headbox design. The present vanes were made of polycarbonate and had a length of $100 \mathrm{~mm}$, a base thickness of $5 \mathrm{~mm}$, and were tapered down to a thickness of $0.5 \mathrm{~mm}$ at the tip.

A series of volumetric headbox flow rates ranging from 3802 down to $1967 \mathrm{l} / \mathrm{min}$, as measured with a magnetic flow meter, were examined for each furnish. The flow rate range corresponded to a headbox consistency range from 0.39 to $0.75 \%$ for the series with $2.0 \mathrm{~mm}$ in fiber length and from 0.40 to $0.79 \%$ for the series with $2.6 \mathrm{~mm}$ in fiber length. First pass retention values over the flow rate range were $83-88 \%$ and $85-90 \%$ for the series with 2.0 and 2.6 $\mathrm{mm}$ in fiber length, respectively.

Before the first experimental point for each furnish, the jet speed was set to about $635 \mathrm{~m} / \mathrm{min}$, corresponding to a speed difference between fiber suspension and wire of about $-(20$ to 25$) \mathrm{m} / \mathrm{min}$ in relation to the point of minimum shear. The headbox pressure was then kept constant over the flow rate series (consistency series). With a jet speed of $635 \mathrm{~m} / \mathrm{min}$, the change in the headbox flow rate corresponded to a change in jet thickness from 18 to $9 \mathrm{~mm}$. The upstream nozzle height of $310 \mathrm{~mm}$, reduced by the total vane thickness $(9 \times 5=45 \mathrm{~mm})$, and the jet thickness range give a range for the nozzle contraction ratio from 17 to 33 . The effect of a change in nozzle contraction ratio on formation is negligible for a kraft furnish (Nordström 2003a).

The system temperature was $40-41^{\circ} \mathrm{C}$ and $\mathrm{pH} 7.5-8.0$.

\section{Wet pressing and drying}

The press section comprised one roll press nip followed by two shoe press nips. The roll nip was double-felted and had a suction top roll with a diameter of $1200 \mathrm{~mm}$ and a blinddrilled mating roll with a diameter of $1000 \mathrm{~mm}$. A linear load of $60 \mathrm{kN} / \mathrm{m}$ was applied in the roll nip. The second and third nips were both single-felted shoe press nips with shoe lengths of $260 \mathrm{~mm}$ and roll diameters of $1225 \mathrm{~mm}$. The second nip had the press roll in the upper-position, and the third nip was inverted with respect to the second. The linear loads in the second and third nips were 700 and 1000 $\mathrm{kN} / \mathrm{m}$, respectively. The shoe-press design enabled online adjustment of the tilt, which represents the ratio between the load on the outgoing side and the load on the ingoing side. The tilt was 1.25 in the second nip and 1.35 in the third nip. The dry solids content after the press section was $38 \%$ for the furnish with a fiber length of $2.0 \mathrm{~mm}$ and 39 $40 \%$ for the furnish with a fiber length of $2.6 \mathrm{~mm}$.

The paper web was wound up after the press section, and the draw between wire section and winder was $2.9 \%$. The paper web was then dried on an off-line dryer with a single drying cylinder. Two longitudinal straps forced the dryer fabric and paper web against the glossy surface of the cylinder, which resulted in essentially restrained drying in both MD and CD.

\section{Analysis}

The machine-made paper and the handsheets were preconditioned and conditioned according to ISO 187. Apparent bulk density was measured according to ISO 534 for the machine-made papers and according to ISO 5270 for the handsheets. Ambertec formation was measured according to SCAN-P 92:09. STFI formation was measured according to NSP Report 5, with two test pieces analyzed per sample. Tensile strength was measured according to ISO 1924-3 and Z-strength according to ISO 15754, but with the pressure increased from 1.4 to $3.0 \mathrm{MPa}$ to ensure sufficient adhesion between tape and paper sample.

Tensile strength efficiency was given by the geometric mean of the tensile indices in MD and CD of the machinemade paper in relation to the tensile index of the handsheets that were made from the same furnish and with similar density. The geometric mean was employed for the machine-made paper, as it is an invariant with respect to the fiber orientation anisotropy for tensile strength (Htun, Fellers 1982). Z-strength efficiency was given by the Zstrength of the machine-made paper in relation to the Zstrength of the handsheets.

Fiber length was measured with the FiberLab instrument of Metso according to ISO 16065-1. The reported fiber length represents the length-weighted average of the contour length. The fiber length measurement also gave the fiber curl index. The content of pine and spruce in the pulp was determined by morphologic analysis. The reported ratio represents an average of eight samples, with 500 fibers classified per sample.

Kappa number was measured according to ISO 302 and drainability (SR number) according to ISO 5267-1. Fines content was measured by fractionation in a Britt drainage jar with a plate-hole diameter of $76 \mu \mathrm{m}$. The water retention value (WRV) was measured according to SCANC 62:00 (with test-pad former) after fines removal. The fiber saturation point (FSP) was measured after fines removal using a solute exclusion technique corresponding to that described by Stone et al. (1968).

All confidence intervals were calculated with a confidence level of $95 \%$.

\section{Results}

The effect of fiber length on strength efficiency in twinwire roll forming was evaluated in a pilot machine investigation. Two furnishes with length-weighted average fiber lengths of 2.0 and $2.6 \mathrm{~mm}$, respectively, were prepared from the same batch of never-dried unbleached softwood kraft pulp by using different refining conditions. Each furnish was examined over a wide range of headbox consistencies.

The machine-to-handsheet ratio for the density was in the range $0.98-1.00$ for all experimental points. Tensile ratios of 3.0-3.4 and 2.3-3.0 were noted for the series with fiber lengths of 2.0 and $2.6 \mathrm{~mm}$, respectively. Table 3 shows the precision in the testing of the mechanical properties of the machine-made paper. 


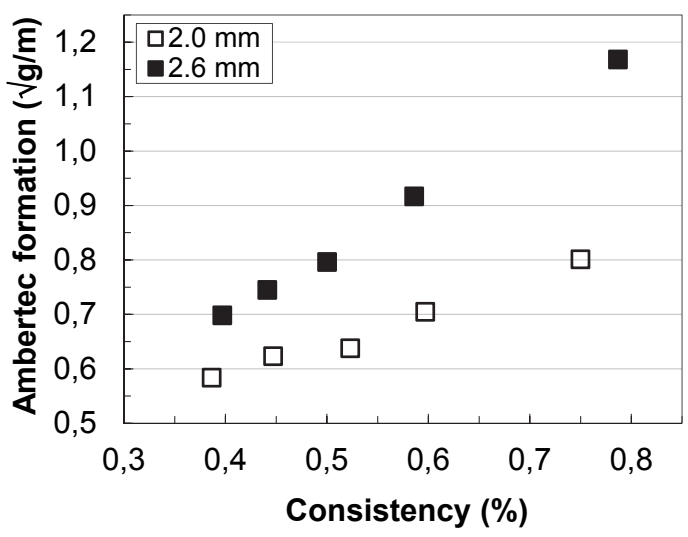

Fig 1 - Ambertec formation vs. headbox consistency for two softwood kraft furnishes with different length-weighted average fiber length. Confidence interval for the individual sample points: $\pm(0.02-0.03) \mathrm{Vg} / \mathrm{m}$

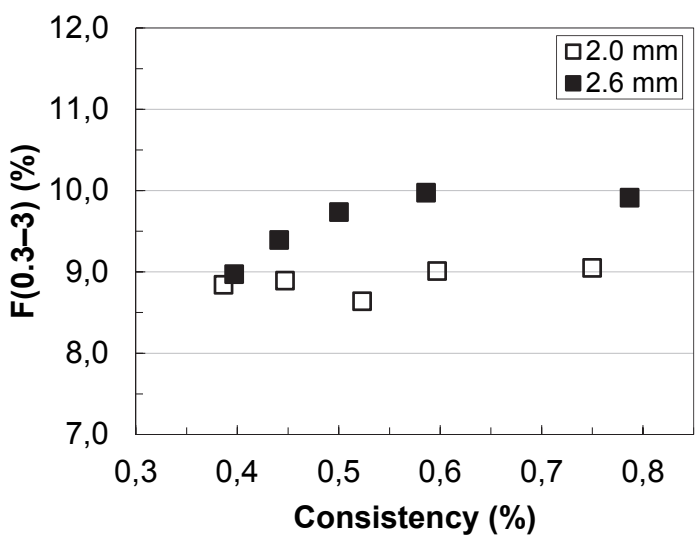

Fig 3 - Small-scale STFI formation vs. headbox consistency for two softwood kraft furnishes with different length-weighted average fiber length.

Table 3 - Relative half-width of the confidence intervals for the mechanical properties of the machine-made paper in the two series (\%).

\begin{tabular}{lccc}
\hline Series & \multicolumn{2}{c}{ Tensile strength } & \multirow{2}{*}{ Z-strength } \\
\cline { 2 - 3 } & MD & CD & \\
\hline $2.0 \mathrm{~mm}$ & $1.9-4.1$ & $2.1-4.4$ & $1.5-2.9$ \\
$2.6 \mathrm{~mm}$ & $3.7-7.1$ & $3.1-5.3$ & $2.0-5.1$ \\
\hline
\end{tabular}

\section{Formation}

The Ambertec formation number showed a close to linear increase (i.e., deterioration) with increasing headbox consistency for both furnishes (Fig 1). The Ambertec formation was worse for the furnish with a fiber length of $2.6 \mathrm{~mm}$ than for the furnish with shorter fibers over the whole consistency range, and the relative difference grew with increasing consistency. The result for the large-scale STFI formation (Fig 2) resembled that for Ambertec formation.

The small-scale STFI formation was similar for the two furnishes at low consistency (Fig 3). The small-scale formation number for the furnish with a fiber length of 2.6 $\mathrm{mm}$ showed an initial increase with increasing

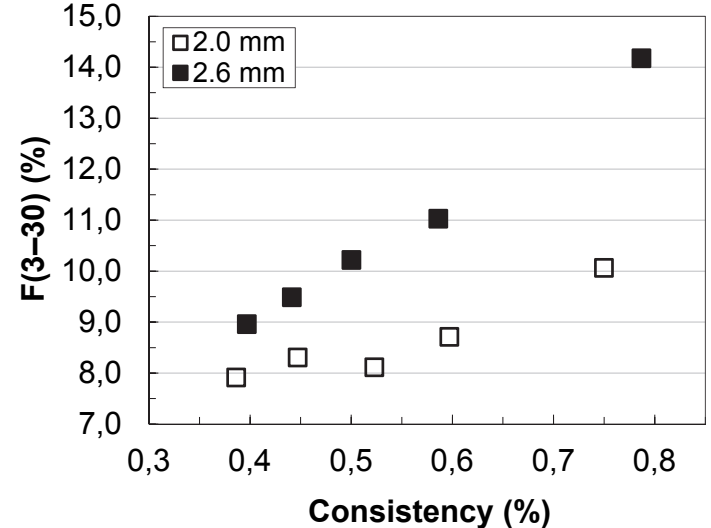

Fig 2 - Large-scale STFI formation vs. headbox consistency for two softwood kraft furnishes with different length-weighted average fiber length.

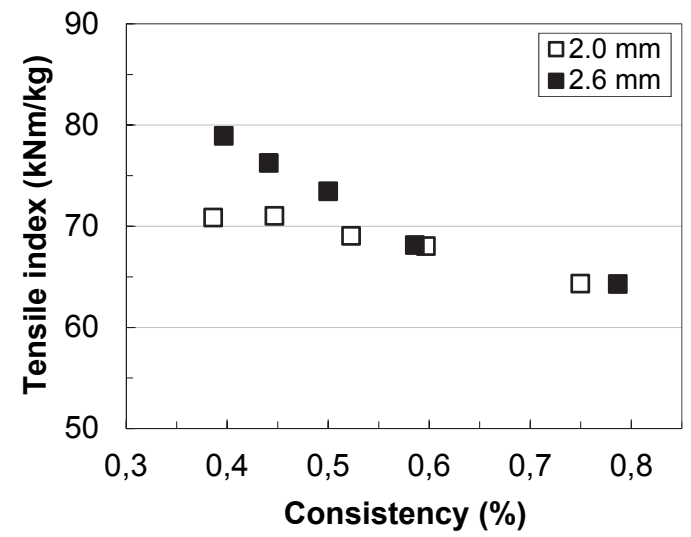

Fig 4 - Tensile index vs. headbox consistency for two softwood kraft furnishes with different length-weighted average fiber length.

consistency, whereas the small-scale formation for the furnish with shorter fibers remained similar. At high consistencies, the small-scale formation was significantly worse for the furnish with a fiber length of $2.6 \mathrm{~mm}$ than for the furnish with shorter fibers.

\section{Tensile strength efficiency}

The furnish with $2.6 \mathrm{~mm}$ in fiber length produced higher tensile strength at low consistency, whereas the two furnishes showed similar tensile strength at consistencies above $0.5 \%$ (Fig 4). The two furnishes exhibited similar tensile strength efficiency at low consistency, whereas the efficiency decreased with increasing consistency at a faster rate for the furnish with longer fibers (Fig 5). At high consistencies, the tensile strength efficiency was substantially higher for the furnish with a fiber length of $2.0 \mathrm{~mm}$. Tensile strength efficiency plotted as function of Ambertec formation shows a single relationship for both furnishes (Fig 6). The tensile strength efficiency was thus similarly affected by a given change in formation, whether produced by a change in fiber length or consistency. 


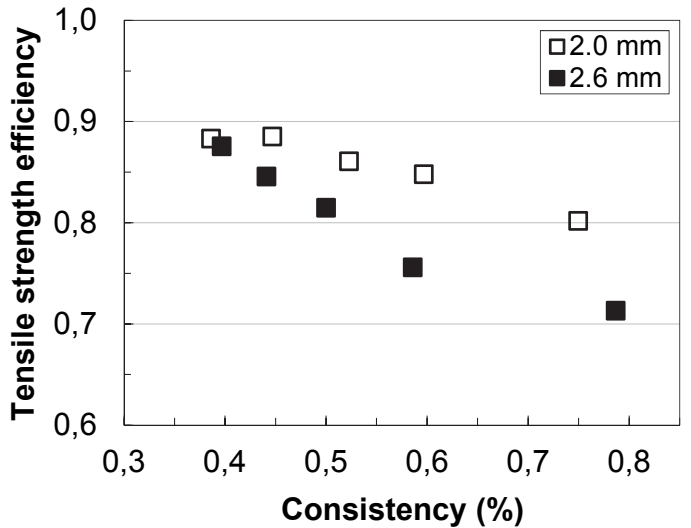

Fig 5 - Tensile strength efficiency vs. headbox consistency for two softwood kraft furnishes with different length-weighted average fiber length.

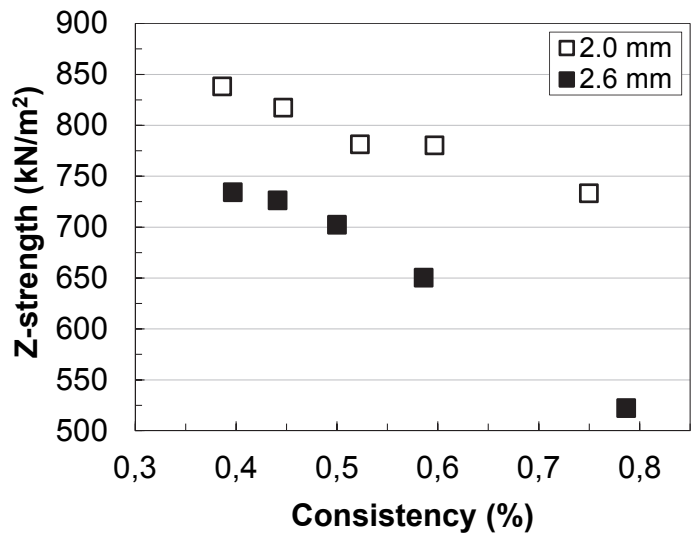

Fig 7 - Z-strength vs. headbox consistency for two softwood kraft furnishes with different length-weighted average fiber length.

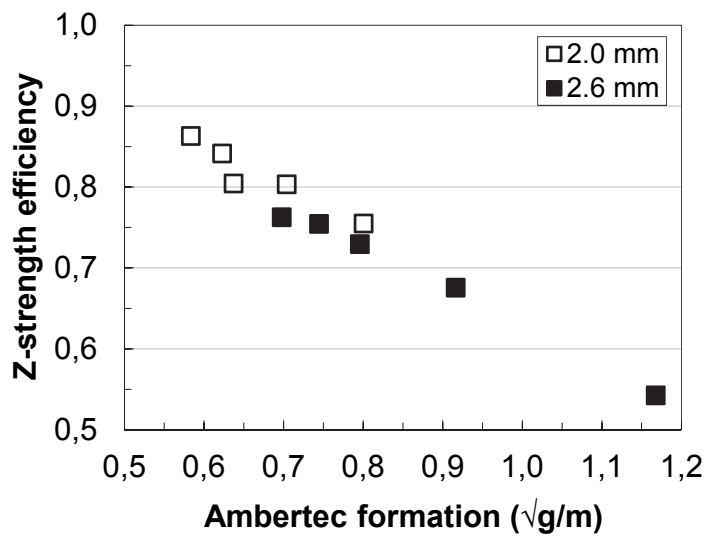

Fig 9 - Z-strength efficiency vs. Ambertec formation for two softwood kraft furnishes with different length-weighted average fiber length. Formation changed through headbox consistency for each furnish.

\section{Z-strength efficiency}

Z-strength (Fig 7) and Z-strength efficiency (Fig 8) decreased with increasing consistency for both furnishes. The furnish with a fiber length of $2.6 \mathrm{~mm}$ showed lower Zstrength and Z-strength efficiency over the whole range

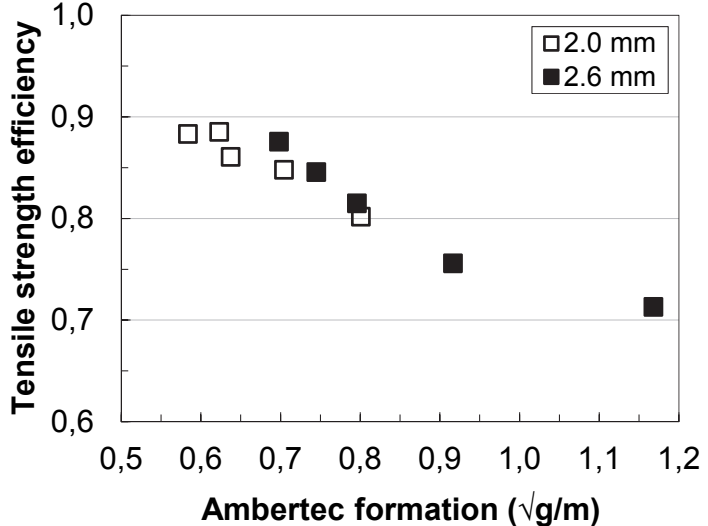

Fig 6 - Tensile strength efficiency vs. Ambertec formation for two softwood kraft furnishes with different length-weighted average fiber length. Formation changed through headbox consistency for each furnish.

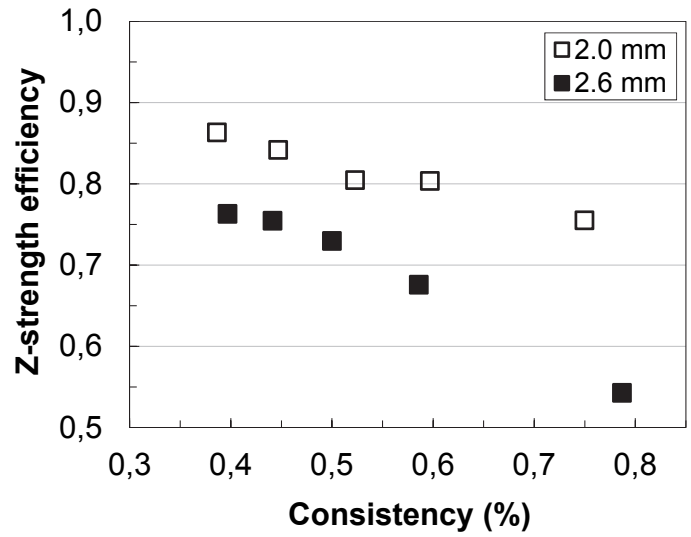

Fig 8 - Z-strength efficiency vs. headbox consistency for two softwood kraft furnishes with different length-weighted average fiber length.

than did the furnish with shorter fibers, and the difference tended to increase with increasing consistency. Z-strength efficiency plotted as a function of Ambertec formation shows a single inverse relationship for both furnishes (Fig 9). Note that a given improvement in formation, through fiber length or consistency, produced a larger relative increase in Z-strength efficiency than in tensile strength efficiency.

\section{Discussion}

The differences in formation (machine-made paper), tensile strength efficiency, and Z-strength efficiency between the two furnishes are attributed to the difference in fiber length, whereas the effect of the differences in drainability, fines content, and fiber swelling (Table 1) is considered negligible. This is supported by results showing that a change in the refining level of never-dried unbleached softwood kraft pulp has an insignificant effect on formation and strength efficiency in twin-wire roll forming if the fiber length remains similar (Nordström, Hermansson 2016)

A change in Ambertec formation through fiber length had evidently an effect on tensile strength efficiency or Zstrength efficiency similar to that of a corresponding 
change in formation through headbox consistency. Note that the limited change in the small-scale STFI formation (floc sizes $0.15-1.5 \mathrm{~mm}$ ) implies that the Ambertec formation (floc sizes $\geq 1 \mathrm{~mm}$ ) largely reflected the total change in local mass distribution. In agreement with the present results, a change in headbox consistency in twinwire roll forming of softwood kraft furnishes was earlier found to produce only a minor change in the small-scale STFI formation (Nordström, Hermansson 2016).

The change in formation of the machine-made paper produced by a change in fiber length is solely attributed to a change in fiber flocculation tendency. This is supported by the insignificant effect of fiber length on the formation of the handsheets, which were prepared at conditions suppressing fiber flocculation. The crowding factor (Kerekes, Schell 1992) has been suggested for characterization of fiber flocculation but appears to be a poor indicator of the effect of fiber length on formation. The crowding factor is proportional to the product of the consistency and the square of the fiber length. The relative difference in crowding factor between two furnishes with different fiber length is consequently unaffected by a change in consistency, whereas the relative difference in formation between the present furnishes increased with increasing consistency.

The faster deterioration in Ambertec formation with increasing headbox consistency for the furnish with longer fibers emphasizes the need for low headbox consistency. There is otherwise a risk that longer fibers only result in poorer formation and lower Z-strength, with no increase in tensile strength despite higher tensile strength potential, as demonstrated by the results.

Z-strength has traditionally been considered closely related to bonding (sheet density) (e.g., Andersson 1978), whereas the importance of formation seems to have been largely neglected. The pronounced relationship observed here between Z-strength efficiency and formation, as changed through fiber length or headbox consistency, is interpreted as revealing the importance of the stress distribution for Z-strength. A more uniform sheet structure, involving fewer and less pronounced floc boundaries, not only in the plane but also in $\mathrm{ZD}$, can be expected to result in a more even stress distribution under tension in $\mathrm{ZD}$, and thereby a higher Z-strength. The relationship between Z-strength and formation may, however, be affected by the furnish composition. In twinwire roll forming of recycled furnishes, rich in fines and ash and with relatively short fibers, no clear effect of formation, as changed by headbox consistency, on Z-strength was observed (Nordström 2003d).

It may be emphasized that the effect of fiber length on Z-strength is considered to be solely related to the effect of fiber length on formation. For the handsheets, neither formation nor Z-strength was significantly affected by fiber length. This is supported by handsheet results of Andersson (1978), who reported similar Z-strength at a given density for four bleached kraft pulps with different fiber dimensions.

\section{Conclusions}

In twin-wire roll forming, an increase in fiber length from 2.0 to $2.6 \mathrm{~mm}$ (length-weighted average) for a softwood kraft furnish not only results in worse Ambertec formation over a wide range of headbox consistencies but also in faster relative deterioration of the formation with increasing consistency. The large-scale STFI formation (3-30 mm wavelength) shows a behavior similar to that of Ambertec formation, whereas the relative effect of fiber length or headbox consistency is substantially smaller for the small-scale STFI formation (0.3-3 mm wavelength). The effect on formation of a change in fiber length is solely attributed to a change in fiber flocculation tendency of the furnish.

An increase in fiber length produces no significant change in tensile strength efficiency at low headbox consistency $(0.4 \%)$ but leads to a faster decrease in tensile strength efficiency with increasing consistency. An increase in fiber length thus results in substantially lower tensile strength efficiency at high consistencies. The effect of fiber length is explained by its effect on formation, and a single inverse relationship between tensile strength efficiency and Ambertec formation number is observed whether the formation is changed through fiber length or headbox consistency. As a consequence of the effect on tensile strength efficiency, the higher tensile strength potential of a furnish with longer fibers may be reflected in higher tensile strength for the machine-made paper only at low headbox consistencies.

An increase in fiber length results in lower Z-strength efficiency over a wide range of headbox consistencies, and the effect tends to increase with increasing consistency. The effect of fiber length is explained by its effect on formation, and a single inverse relationship between Zstrength efficiency and Ambertec formation number is observed whether the formation is changed through fiber length or headbox consistency. A given change in formation through fiber length or headbox consistency produces a larger relative change in Z-strength efficiency than in tensile strength efficiency. As the Z-strength potential of the furnish remains similar when increasing fiber length, the decrease in Z-strength efficiency is directly reflected in lower Z-strength for the machinemade paper.

\section{Acknowledgments}

Mr. Olof Öhgren (former Senior Process Engineer at SCA Obbola $A B$ ) is thanked for organizing the supply of the pulp as well as for interesting discussions.

\footnotetext{
Literature

Andersson, M. (1978): Aspects of Z-strength in pulp characterization. Dissertation. Pulp Technology, Royal Institute of Technology, Stockholm.

Hallgren, H. and Lindstrom, T. (1989): The influence of stock prep on forming efficiency. Paper Technol. Ind. 30(2): 35.

Htun, M. and Fellers, C. (1982): The invariant mechanical properties of oriented handsheets. Tappi 65(4): 113.

Kerekes, R.J. and Schell, C.J. (1992): Characterization of fibre flocculation regimes by a crowding factor. J. Pulp Paper Sci. 18(1): J32.
} 
Nordström, B. (1995): Effects of headbox design and dewatering conditions on twin-wire forming of TMP. Dissertation. Dept. Pulp \& Paper Technology, Royal Institute of Technology, Stockholm.

Nordström, B. (2003a): Effects of pulp type and headbox design on anisotropy and other sheet properties in twin-wire roll forming. Nord. Pulp Paper Res. J. 18(3): 288.

Nordström, B. (2003b): Effects of roll wrapping angle and headbox flow rate in twin-wire roll-blade forming of a linerboard furnish. Nord. Pulp Paper Res. J. 18(3): 255.

Nordström, B. (2003c): Fourdrinier versus twin-wire roll forming-effects on fiber orientation anisotropy and other sheet properties. Nord. Pulp Paper Res. J. 18(3): 262.

Nordström, B. (2003d): Influence of consistency in twin-wire roll forming of two recycled liner furnishes. Nord. Pulp Paper Res. J. 18(3): 303.

Nordström, B. (2003e): Twin-wire blade forming versus roll forming of a linerboard furnish-effects on tensile strength and formation. Nord. Pulp Paper Res. J. 18(3): 245.

Nordström, B. (2006): Twin-wire roll forming of mechanical base paper from three furnishes - effects on formation and mechanical properties. Nord. Pulp Paper Res. J. 21(3): 349.

Nordström, B. (2014): Effects of fiber dimensions on compression strength of handsheets. Nord. Pulp Paper Res. J. 29(4): 711.

Nordström, B. and Hermansson, L. (2016): Effect of refining on strength efficiency in twin-wire roll forming of never-dried unbleached softwood kraft pulp. Nord. Pulp Paper Res. J. 31(4): 624.

Nordström, B. and Norman, B. (1994): Development of the STFI-former. Nord. Pulp Paper Res. J. 9(3): 176.

Nordström, B. and Norman, B. (1996): Effects on paper properties and retention of the proportion of roll dewatering during twin-wire roll-blade forming of TMP. J. Pulp Paper Sci. 22(8): J283.

Page, D.H. (1969): A theory for the tensile strength of paper. Tappi J. 52(4): 674

Röding, S. and Norman, B. (1986): FEX, The new STFI experimental paper machine. Tappi J. 69(1): 94.

Stone, J.E., Scallan, A.M. and Abrahamson, B. (1968): Influence of beating on cell wall swelling and internal fibrillation. Svensk Papperstidning 71(19): 687. 